\title{
O GÊNIO RÓDIO DE ALEXANDER VON HUMBOLDT
}

\section{The Alexander Von Humboldt's Rhodium Genius}

\author{
Roberison Wittgenstein Dias Silveira \\ silveira_r@yahoo.com.br \\ Universidade Federal de Alagoas, Maceió, Alagoas, Brasil
}

Artigo recebido em 16/10/2014 e aceito para publicação em 13/03/2015

RESUMO: Neste artigo analisaremos o Gênio Ródio de Humboldt e as implicações filosóficas da sua publicação. A tarefa essencial consiste em delinear as possibilidades interpretativas e o caráter filosófico-sistemático da obra, ponderando as possibilidades interpretativas desta publicação em suas muitas modificações ao longo da vida de Humboldt. Considerando o importante debate estético do período e a forma como razão e sensibilidade se tornaram mutuamente dependentes na solução idealista romântica, o artigo visa esclarecer a dimensão representativa do Gênio Ródio e sua importância na transformação que ocorreu entre os anos de 1795 (data da primeira publicação) e 1849 (data da última edição dos Quadros da Natureza). Ao final, adentrando o debate científico, estético e filosófico, teremos a oportunidade de ver como Humboldt, ao confluir em sua obra as modificações interpretativas do Gênio Ródio se tornou o primeiro a incorporar cientificamente o conceito de paisagem como duplo objetivo/subjetivo sob as bases do discurso estético-filosófico na construção de uma ciência do Cosmos.

Palavras-Chave: Gênio Ródio. Humboldt. Paisagem.

ABSTRACT: In this paper we will analyze the Humboldt's Rhodium Genius and philosophical implications of its publication. The essential task is to outline the interpretive possibilities and philosophical-systematic character of the work, pondering the interpretive possibilities of this publication in the course of the Humboldt life. Considering the important aesthetic debate of the period and as reason and sensibility have become mutually dependent on romantic idealist solution, the paper seeks to clarify the representative dimension of Rhodium Genius and its importance in the transformation that occurred between the years 1795 (date of first publication) and 1849 (date of the last edition of Frames of Nature). At the end, entering the scientific, aesthetic and philosophical debate, we will have the opportunity to see how Humboldt' Rhodium Genius allowed the first incorporating scientific of the landscape concept as dual objective/ subjective in the construction to an aesthetic-philosophical science of the Cosmos.

Keywords: Rhodium Genius. Humboldt. Landscape. 


\section{INTRODUÇÃO}

A vida e obra de Humboldt são marcadas por um conjunto de modificações importantes que ocorreram no âmbito da Ciência, da Arte e da Filosofia. O artigo A força vital ou o Gênio Ródio, publicado pela primeira vez em 1795 no periódico Die Horen de Schiller, guarda um elemento de ligação capaz de associar as pesquisas iniciais do Humboldt cientista com os trabalhos maduros de sua ciência artísticofilosófica do Cosmos.

Como homem de seu tempo, Humboldt vivenciou as transformações que marcaram a passagem do século XVIII para o século XIX, atuando direta e ativamente em todas elas. A princípio, envolveu-se com a discussão sobre o caráter mecânico ou teleológico da natureza; uma discussão que levantava dúvidas se a dinâmica e atividade do mundo podiam ser meramente descritas pelos princípios causais mecânicos ou se demandariam outro tipo de causa teleológica, capaz de ordenar as formas e dinâmicas para uma finalidade ainda incompreendida. O Gênio Ródio, de que trata este artigo, surge, em um primeiro sentido, na aliança estabelecida por Humboldt com o chamado vitalismo científico setecentista; momento em que também flerta com outras vias propositivas atentas ao caráter teleológico natural, mas já preocupadas com um conhecimento capaz de ultrapassar os limites formais de uma surrada ciência iluminista. Na extensão do movimento romântico alemão, a obra humboldtiana vai assumindo novos contornos, recontando aspectos fundamentais da ciência, ao tempo que olha para elementos simbólicos e de associações pouco usuais no campo da formalidade analítica do século XVIII.

Compreender este percurso é fundamental no sentido de entender a centralidade assumida pela paisagem na leitura geográfica de Humboldt e, acima de tudo, é imprescindível na tarefa de se apoderar da complexidade envolvida na construção de uma nova ciência, chamada de ciência humboldtiana do Cosmos, de onde emergiu a perspectiva humanonatural da Moderna Geografia.

Trilhando este caminho, descobrimos no Gênio Ródio a transformação toda operada no pensamento e vida científica de Alexander von Humboldt, compreendendo que no reeditar do texto novas significações foram sendo dadas e, nesse mudar, os rumos da assimilação simbólica e transcendental do movimento romântico alemão se aliaram progressivamente com a perspectiva vital, assumindo definitivamente a unidade cósmica universal.

\section{A FORMAÇÃO INICIAL DE HUMBOLDT}

Para bomandamento da análise, delinearemos alguns acontecimentos da vida de Humboldt associados à primeira publicação do Gênio Ródio; acontecimentos que, de uma forma ou de outra, estiveram intimamente ligados à mudança estrutural da forma de pensar humboldtiana que desaguaria anos mais tarde na sistematização da ciência do Cosmos e sua leitura geográfica integradora.

Em 1795, a grande questão intelectual na vida de Humboldt girava em torno da aceitação ou recusa de causas fundamentais por detrás dos fenômenos mais controversos no campo da botânica, fisiologia e mineralogia. Para entender isso, voltamos até o ano de 1787, quando Alexander von Humboldt foi admitido na Universidade de Frankfurt.

Entre os anos de 1787 e 1789 Humboldt teve contato com aspectos básicos da discussão botânica e, especificamente nessa questão, passou a prestar atenção para as formas de associação entre o ambiente em que se produziam as plantas e as formas assumidas por seu desenvolvimento vegetal. No estudo de composição e conservação de plantas, estudou com detida atenção a forma como situações bastante tênues mudavam por completo a forma de progressão das planatas nas estufas e jardins. Estas primeiras informações acadêmicas iniciam Humboldt nas controvérsias filosófico-científicas do período, que por esse tempo giravam em torno de uma busca explkicativa para o fenômeno da variação formativa das planatas para além do arranjo mecanicista largamente difundido e empregado na bem sucedida filosofia natural, ou física. A ampliação dessas discussões e o entendimento progressivo da complexidade envolvida no debate tomam outra proporção quando, em 1789, Humboldt vai para Gotinga.

Nesse novo ambiente acadêmico, decididamente mergulhado no centro dessa questão 
teleológica do desenvolvimento natural, recebe Humboldt a orientação de eminentes professores como Christian Gottlob Heyne (1729-1812), Karl Frederic Eichhorn (1781-1854), além de Johann Friedrich Blumenbach (1752-1840), que lhes ensinam fisiologia, ciências da natureza e anatomia comparada. Especificamente aqui, cabe destaque a Blumenbach. Ele estava a par das principais divergências entre o mecanicismo e as perspectivas teleológicas, muito embora tenhamos que considerar que as principais conquistas de Blumenbach nesse terreno tenham acontecido depois da passagem de Humboldt por Gotinga, ou seja, já na década de 1790 . Ainda assim, é certo e notório que Blumenbach já estava definitivamente detido no assunto, de onde podemos compreender como começa a ser construída no pensamento de Humboldt a necessidade de lidar com perspectivas de integração divergentes daquelas pré-estabelecidas pelo modelo mecanicistas apregoados pelas ciências consolidadas. A preocupação geral em torno dos elementos ocultos da natureza, as formas teleológicas de encadeamento somadas à formação na área de geologia e zoologia constituem a base da primeira fase do pensamento humboldtiano.

A chegada de Humboldt a Freiberg, grande centro científico natural em 1791, se deve ao seu trabalho Observações mineralógicas sobre o baixo Reno, elaborado depois da viagem com Georg Forster (1754-1794) pelo Baixo Reno, passando por Holanda e França. As orientações neptunistas do trabalho atraíram o interesse de Abraham Gottlob Werner (1749-1817), que enxergava no jovem Humboldt a possibilidade de extensão das suas pesquisas. Por esse tempo, Humboldt frequenta em Freiberg os cursos de Geologia, Mineralogia, Topografia, Tecnologia Mineira, Física, Direito e Matemática, dedicandose por conta própria à Paleontologia e à Química (GAYET,1995). Aqui solidifica-se definitivamente o conhecimento básico de Humboldt acerca dos problemas que estavam diluídos em todos os campos disciplinares no final do século XVIII e começaram a ser apreendidos ainda nos anos de Frankfurt. A horda de transformações que ocorriam nesse final de século e que fundamentaram a ciência do século XIX adentraram por completo as preocupações ordinárias de seu itinerário de estudos e pesquisas, expressando nos escritos do período o engajamento com as dificuldades mais emblemáticas da ciência da natureza.

Não obstante, é o cargo como assessor do Departamento de Minas de Berlin, em 1792, que define o rumo de suas publicações futuras e direciona a pesquisa de Humboldt para aquele escrito do Gênio Ródio. Ele não consegue restringir-se ao trabalho burocrático; desce até as minas; trabalha ativamente na área. Revelam-se nesses estudos as inquietações da juventude, a predisposição para o trabalho de campo, para a análise empírica. Essa sua dedicação à pesquisa the vale, inclusive, um envio pela Europa para pesquisar áreas mineralógicas, que breve lhe suscitarão os anseios de estender suas análises às regiões mais longínquas do planeta, às terras exóticas que aprendera a amar em suas primeiras lições. Nesse período, chama a atenção de Humboldt as indagações sobre a relação existente entre o desenvolvimento das plantas e a luminosidade ambiente, graças às suas observações e análises nas áreas pouco iluminadas das minas. Essa iniciativa será fundamental nos seus trabalhos futuros, sobretudo nas pesquisas realizadas no continente americano e na compreensão de uma interconexão entre os elementos do mundo natural. Antes disso, suas investigações fitogeográficas o conduzem à discussão elétrica. Gayet (1995) dirá que o direcionamento da pesquisa fitogeográfica para as polêmicas da eletricidade se dará porque Humboldt percebe a relação entre o crescimento das plantas e o estímulo fornecido por corpos externos. O que se deve destacar, entretanto, é a noção de que existe no processo de desenvolvimento das plantas um agente que, há esse tempo, se correlaciona com a eletricidade ou sua geração. Nessa visão de final de XVIII os seres vivos possuem uma fonte interna de energia, e mais, o conjunto dessas forças atua e é transmitido mutuamente entre os seres no desenvolvimento natural.

Abre-se com essa discussão sobre a eletricidade a polêmica envolvendo a visão geral de natureza, mais especificamente, instaura-se em seus trabalhos a discussão acerca dos princípios pelos quais o saber deve orientar-se na análise e compreensão da vida. O que se colocava em xeque 
com os experimentos botânicos e fisiológicos elétricos no final do século XVIII, cujo representante maior foi Galvani, era justamente aquela adoção do método matemático-experimental amplamente discutida no contexto entre os cientistas naturais.

A recusa a uma concepção de natureza estritamente mecânica é o primeiro passo científico na carreira de Humboldt como pesquisador. Ele inicia sua produção de maior vulto exatamente no limiar deste método, na recusa geral de uma via estritamente mecanicista para os fenômenos que habitam os reinos da natureza, especialmente o vegetal.

Entendemos agora o que se passa com Humboldt e com o contexto geral das ciências naturais no ano de 1795 quando vem a público o trabalho que analisaremos neste artigo: A Força Vital ou o Gênio Ródio. A publicação original no Die Horen trata precisamente dessa ampla discussão teleológica e da concepção vitalista, capaz de pensar a natureza a partir de causas e elementos ocultos intangíveis para a esfera do método matemáticoexperimental newtoniano.

\section{O GÊNIO RÓDIO}

O escrito A Força Vital ou o Gênio Ródio humboldtiano conta a misteriosa história de um quadro interpretado por Epicarmo, um velho sábio. Uma imagem intrigante circula em Siracusa como um grande enigma, sem que nem ao menos o autor da obra tenha sido identificado. A figura central do quadro perdido que vaga de mão em mão nas ruas da cidade é a de um gênio, altivo, robusto, tendo pousada nas costas uma borboleta e, na mão direita, uma tocha ardendo em fogo. Num primeiro plano, em torno do gênio, se dispõem pessoas nuas, envoltas em um semblante de tristeza, de desfalecimento, agarrando uma as outras pelas mãos, ligadas numa corrente e submetidas à imagem daquele vigoroso ser ao centro. Intrigante, o significado parece difuso e submetido a inúmeras interpretações. Quando, enfim, nova pintura aparece, em meio a relíquias agrupadas em novo empreendimento marítimo, não tarda a ser reconhecida, pelo estilo, cores e imagem, como a continuação do quadro enigmático do Gênio
Ródio. Esta segunda imagem tem, igualmente, um gênio ao centro, mas já não se lhe encontra às costas a borboleta pousada e, em sua mão, a tocha que então ardia encontra-se apagada; seu semblante é de morte, sucumbido e derrotado ao centro do quadro. Não obstante, aqueles que se mostravam ligados, unidos por suas mãos, já não estão; bailam e saltam alegremente em êxtase e felicidade.

Epicarmo, enfermo, já no leito de morte, recebe então estas duas imagens. Ao contemplar por alguns instantes as figuras chama seus discípulos e lhes diz:

Durante sessenta anos tenho meditado acerca das molas íntimas que movem a natureza, e da diversidade das substâncias, e só hoje vem o Gênio ródio mostrar-me, de maneira manifesta, o que até agora apenas pude suspeitar. Se o dualismo dos sexos estabelece entre os seres viventes uma aliança benéfica e fecunda, é necessário que a matéria bruta, de que é composta a natureza inorgânica, seja movida por molas semelhantes. Já no caos escuro se condensava ou difundia a matéria, conforme era atraída ou repelida, amiga ou inimiga. $\mathrm{O}$ fogo celeste segue os metais; o ímã abrasa-se ao contacto do ferro; o âmbar friccionado põe em movimento os corpos ligeiros; a terra mistura-se com a terra; o sal separa-se da água do mar que se evapora(...) Tudo na natureza inanimada anseia por se unir ao objecto que o solicita.(...) A existência não é senão o ponto de partida de onde cada coisa se lança em novas combinações (HUMBOLDT, 1953, p. 198-199; 1930, p. 645-646).

A figura do Gênio, sua robustez, a borboleta que lhe pousa às costas, tudo isso representaria a força vital; o fundamento primeiro pelo qual se dispõe a todo existente sua atividade. No primeiro quadro, as pessoas aflitas, encadeadas por seu desfalecimento, esperam essa força, imploram com seus olhares a vida que anima o Gênio. A medida da vida, essa força, é buscada como a única coisa provida de sentido. Um instante e aquele que era o centro da força, o Gênio que a detinha e incorporava, já não é; 
já não se vê nada além do que a falência decadente de quem foi abandonado pela força elementar da vida. Seu instante de morte, o momento em que a borboleta sai em voo livre, é o de nascimento para outros, que, gozando a força vital, já não se ligam em sofrimento, mas fazem da morte nova vida, o processo contínuo de um reproduzir da existência.

As substâncias terrestres reconquistaram os seus direitos. Por muito tempo privados dos gozos por que ansiavam, e livres, por fim, das suas cadeias, seguem com ímpeto selvagem o instinto que as solicita. O dia da morte é para elas um dia de himeneu. Deste modo a matéria inerte, animada pela força vital, tem passado por uma série interminável de gerações, e talvez que tenha servido de invólucro ao espírito divino de Pitágoras a mesma substância em que, momentos antes, um verme arrastou a sua existência miserável. (HUMBOLDT, 1953, p. 200; 1930, p. 647648)

Epicarmo anuncia esse caminho e o seu próprio, dizendo nele já se esvair essa força elementar, que, abandonando-o, lança-se em nova vida, em força harmoniosa que mantém ininterrupta a atividade do mundo. "Sinto que a força vital debilitada não há de dominar em mim, durante muito tempo, a substância terrestre. A matéria reclama a sua liberdade." (HUMBOLDT, 1953, p. 200; 1930, p. 648).

Analisando o texto, recobrando algumas passagens significativas, podemos ver claramente uma série de questões importantes. "Se o dualismo dos sexos estabelece entre os seres viventes uma aliança benéfica e fecunda, é necessário que a matéria bruta, de que é composta a natureza inorgânica, seja movida por molas semelhantes." Recuperando a discussão acerca da esfera inorgânica geológica do período, vemos que há algumas tentativas de transposição das conquistas e indagações do reino vegetal para esse campo, como por exemplo a tentativa linnaeuniana de interpretar a geração e formação mineral a partir do salino macho e da terrena fêmea. Todavia, o elemento central da discussão parece dizer respeito ao elemento oculto que orienta as oposições e fazemnas harmonizar-se na consagração da substância da natureza. "Tudo na natureza inanimada anseia por se unir ao objecto que o solicita.(...) A existência não é senão o ponto de partida de onde cada coisa se lança em novas combinações." O conjunto de descobertas, especialmente envolvendo a eletricidade e o magnetismo davam conta de forças contrapostas que, em sua divergência, reclamavam enquanto opostas uma unidade. A diversidade das forças formava, nessa perspectiva, uma unidade do mundo. Aquela substância oculta, inatingível para a física mecanicista, era o que jazia como causa intangível, como elemento imponderável da vida e, por isso, inacessível aos modelos newtonianos.

Toda a dificuldade enfrentada pelo mecanicismo no reino do orgânico, dificuldades estas conhecidas por Humboldt em sua formação botânica, davam conta desse questionamento com relação ao domínio sistemático da natureza, aí inclusa a esfera inorgânica. A explicação aqui está associada com a dissolução da força vital no mundo, dispersa e atuante em cada corpo vivente e transitando na natureza no encadeamento de vida e morte. Aquilo que percebemos como inanimado resguarda também a matéria fundamental da vida, a capacidade formadora de nutrientes e propriedades que se substanciam em tecidos, em órgãos, na passagem para a planta, na sustentação dos vermes, no alimento da ave. Toda a natureza é indistinta e nela se vê apenas o transitar da força da vida, assim como na imagem que circulava em Siracusa; do gênio saia o elemento vital, elevando a existência da borboleta em pleno voo e da multidão solicita que lhe tomava a mão.

Em termos sistemáticos, esta interpretação de Humboldt parece uma ligação do elemento oculto que emerge na discussão teleológica vitalista com a composição sistemática de Diderot, em que se percebe uma unidade dos processos naturais e, especialmente, das esferas orgânica e inorgânica. Diderot recusa o método matemático como fórmula para a compreensão da realidade e, nesse sentido, está também dissociado da interpretação newtoniana da Terra; o que dá margem para que esta visão sistemática tenha servido no projeto de contraposição ao mecanicismo por parte de 
Humboldt. Outra explicação pode também ser dada a partir da associação de Humboldt com o pensamento de Buffon, que, nesse embate, colocase também contra o mecanicismo, recuperando a ligação sistemática Leibniz-wolffiana. Essa via sistemática buffoniana dá conta de uma dinâmica da natureza em associação no tempo, o que parece bastante próximo da perspectiva inicial de Humboldt que, para além da força vital como elemento oculto, já concebe, ainda que em linhas bastante imprecisas, uma unidade da natureza. A favor dessa perspectiva integradora de Buffon há uma série de citações do próprio Humboldt, rendendo homenagens a este que, para ele, percebeu como poucos o caráter dinâmico da natureza no campo da História Natural.

Vale lembrar também que naquele final de século dominava na Alemanha a recusa ao aparato estritamente formal para a compreensão da natureza (Sturm und Drang). Humboldt, a princípio, tem uma boa relação com os expoentes do movimento, mais superficial com Schiller e um pouco mais consistente com Goethe, já no ano de 1793, por ocasião da publicação de sua Florae Fribergensis Specimen. De fato, no Gênio Ródio, pela primeira vez, Humboldt pretende um tratamento simbólico das forças ocultas e, nesse sentido, pode-se compreender este ensaio como uma forma de manifestar sua simpatia com as ideias fundamentais do movimento romântico nascente. Entretanto, o fundamento primordial do artigo é, sem dúvida, a força vital expressa nas atividades científicas, aquela mesma que povoa as investigações de Galvani e aparece como uma energia animal, fonte da vida e dos movimentos.

Nessa interpretação das forças ocultas elas mostram-se difundidas na natureza, habitando os corpos e transitando pelas esferas orgânica e inorgânica. Alguns anos depois o próprio Humboldt recusa essa força vital dispersa nos animais e plantas, abandonando as concepções vitalistas diante das evidências empíricas de geração da suposta energia animal pelas propriedades químico-físicas das placas envolvidas nos experimentos galvânicos. Os argumentos de Volta pareceram suficientes para Humboldt e, efetivamente, depois da recusa geral do vitalismo na ciência, não havia meio de sustentar, e nem porquê, essa concepção de natureza. Humboldt
(1953; 1930) afirma: “[...] a reflexão, e os estudos constantes no domínio da fisiologia e da química, modificaram profundamente a minha antiga crença acerca das forças vitais distintas." (p. 202; p. 650). Ora, é justamente o papel desempenhado aqui pelos estudos eletroquímicos em conjunto com Johann Ritter (1776-1810) que justificam esse abandono de múltiplas causas ocultas ou o que seria para Galvani a força vital animal. J. Ritter se associa à Humboldt num trabalho sobre a excitabilidade nervosa dos animais, chegando pouco tempo depois à conclusão de uma força única baseada na eletroquímica como fonte da unidade orgânica da Terra. A fundamentação Química de J. Ritter teria levado Humboldt a integrar sua visão dos fenômenos da força vital com os experimentos da Química, ou seja, teria permitido ligar estes fenômenos a partir de uma associação da matéria orgânica com os mesmos pressupostos e fundamentos das transformações gerais dos elementos inorgânicos (relação também intentada por Davy na associação e experimento dos gases inorgânicos com a transformação do humor e da condição física orgânica). Precisamente aqui Humboldt se dissocia da concepção de causa oculta, mantendo no esquecimento o artigo do Gênio Ródio.

\section{A RECUPERAÇÃO DO GÊNIO RÓDIO E SEU SIGNIFICADO SISTEMÁTICO EM HUMBOLDT}

No entanto, o curioso desse velho artigo de 1795 é que ele reaparece na segunda e terceira edição dos Quadros da Natureza, em 1826 e 1849. No intuito de compreender sistematicamente Humboldt, merece atenção o novo significado atribuído à força vital. Os anos que seguem à publicação do Gênio Ródio são bastante intensos para Humboldt. Em um curto intervalo de tempo ele fortifica as relações que havia iniciado com os principais expoentes do pré-romantismo e, na mesma medida, com as ideias e personagens mais importantes do nascente romantismo alemão. Sua estada em Jena nos anos de 1796 e 1797 certamente modificou por completo a sua vida, sendo capaz de, a partir desse momento, tomar todo o seu conhecimento formal a partir de uma perspectiva mais abrangente e reveladora. 
Como Humboldt mesmo dirá em uma de suas cartas no ano de 1806:

[...] apesar dos mil fenômenos e imagens que ocupam meus sentidos, o novo se tornava em seguida familiar e o que parecia exteriormente desconhecido se adaptava facilmente às antigas imagens; reconhecia nos bosques do Amazonas, e sobre os contrafortes dos Andes, que o mesmo sopro anima a mesma vida de um polo a outro nas pedras, nas plantas, nos animais e no dilatado peito do homem. O sentimento da grande influência de Jena me persegue por todas as partes, já que as ideias de Goethe a respeito da natureza me transmitiram e, por assim dizer, me dotaram de novos órgãos. (HUMBOLDT, s.d., p. 143, trad. nossa.)

Todas as perspectivas que pareciam já constituídas e alojadas na sua forma de pensar ganham novos traços e feições, produzindo uma redefinição do seu propósito de integradamente conceber a natureza. Em Jena a perspectiva de um elemento fundamental por detrás dos fenômenos responsável pela dinâmica da realidade era matéria corrente. $\mathrm{O}$ princípio reflexivo kantiano havia penetrado à causa romântica via Fichte e, no processo de resignificação sistemática, deixou de ser meramente uma atividade reflexiva judicativa para incorporar-se à dinâmica da natureza, ainda que ela mesma fosse concebida em sua íntima relação com a autoconsciência. Defendemos que a nova concepção de força vital em Humboldt se baliza nessas modificações que tomaram corpo no idealismo romântico e, neste trabalho, pretendemos mostrar como esse legado filosófico-estético lhe permitiu estruturar sua visão integrada do Cosmos.

Vimos que os elementos ocultos que nortearam Humboldt na primeira publicação do Gênio Ródio estavam ligados com o vitalismo, oriundo da associação das descobertas elétricas e fisiológicas, além de uma visão sistemática temporalizante e assentada na ampla relação entre os elementos naturais, sejam eles da esfera orgânica ou inorgânica. Entretanto, no romantismo, o caráter teleológico da natureza resguarda algumas singularidades que merecem ser discutidas para a melhor compreensão do projeto humboldtiano de ciência. Uma citação é bastante elucidativa com relação a esse caráter diferenciado da finalidade na concepção sistemática que segue nos Quadros da Natureza e que retrata o papel que a Naturphilosophie romântica desempenhou em sua forma de fazer ciência.

A única conclusão positiva da nossa discussão é que, até aqui, nenhum princípio, nem a acção dos meios, nem o hábito, nem a eleição natural, podem explicar as apropriações orgânicas sem a interpretação do princípio de finalidade. A eleição natural não guiada, submetida às leis de um maquenismo puro, e determinada exclusivamente por acidentes, parece-me, com outro nome, o acaso de Epicuro, tão estéril e tão incompreensível como ele; mas a eleição natural, guiada a priori por uma vontade precedente, e dirigida para um fim preciso, por leis intencionais, bem poderia ser o meio que a natureza escolheu para passar de um grau do ser a outro, de uma a outra forma, para aperfeiçoar a vida no universo e elevarse por um processo contínuo, da mónada à humanidade. (HUMBOLDT, 1953, p. 323)

Em primeiro lugar vale destacar o caráter a priori de uma "vontade precedente", "dirigida para um fim preciso". Entre outras coisas, há a consideração de um elemento ativo que torna produtiva a natureza, que permite que ela se apresente em seu caráter de ordenação a fins. A consideração da atividade pelo transcendental é matéria recorrente no romantismo e idealismo alemão, ainda que essa designação de princípio faça mais referência à pura atividade reflexiva do Eu fichtiano, ou mesmo ao caráter singular de um a priori kantiano na Crítica do Juízo, visto que trata de um a priori que não é determinado pela razão, mas pela forma de proceder da própria faculdade do juízo na procura de leis universais para a natureza. $\mathrm{O}$ termo vontade também conota uma ligação entre o fundamento da atividade ideal no mundo e da atividade ideal no homem, posto que pretende na analogia a designação de um fim norteado não por causas determinísticas, mas tomadas 
livremente como objeto do querer. Schopenhauer também é bastante hábil em resgatar este fundamento a partir da Vontade, e teremos oportunidade de ver que a conformação com Humboldt não se limita a essa mera associação de conceitos.

Antes de apropriadamente traçarmos um quadro de ligações, há de se ressaltar, ainda com relação à citação acima, a passagem que diz: "poderia ser o meio que a natureza escolheu para passar de um grau do ser a outro, de uma a outra forma, para aperfeiçoar a vida no universo e elevar-se por um processo contínuo, da mônada à humanidade." As mudanças e transformações se revelam ali na forma, na alternância da imagem produzida pela natureza, além de partirem da mônada para a humanidade. $O$ caráter produtivo da natureza configura no homem o seu fim, sua máxima realização como o ser natural que toma consciência da própria natureza; um ser tal que, no apelo à mônada leibniziana, parte do elemento mais simples e fundador da realidade para atingir o grau máximo de desenvolvimento de si e do mundo sob a forma da figura humana. A perspectiva de mônada é retomada numa perspectiva crítica na proposição filosófico-sistemática de Schelling. Portanto, nessa simples passagem e na análise de muitos elementos que ainda serão alvo de investigação, destacamos que o caráter de finalidade nos Quadros da Natureza e nas obras que se seguirão tem uma conotação diferente da mera consideração finalística da ciência, bem como de sua representação vitalística-galvânica na esfera orgânica.

Como havíamos dito, o caráter central do Gênio Ródio está na existência de uma força oculta atuante na produção da natureza, designando uma unidade do mundo e uma progressão. Cabe compreender, portanto, o que significa essa passagem na segunda edição dos Quadros da Natureza em 1826; acerca disso, vale notar o que Humboldt fala ao tratar das enguias elétricas que, no continente americano, atacavam os cavalos quando passavam pela água.

Tal é o combate de cavalos e de peixes. A força, que converte em arma viva e invisível a estes habitantes das águas, não é senão essa que, desenvolvida pelo contacto de partes úmidas e heterogêneas, circula por todos os órgãos de animais e plantas, incendeia e faz ressoar a imensa abóboda do céu, atrai o ferro e rege a marcha regular e obstinada da agulha magnética. Todos estes fenômenos nascem de uma fonte única, como as cores em que se decompõe o raio luminoso, todos se resolvem numa força eterna e universalmente espalhada. (HUMBOLDT, 1952, I, p. 25-26, grifo nosso; 1930, p. 50)

Aqui está expressa de maneira bastante clara, no mesmo livro que traz o novo significado do Gênio Ródio, a ligação entre a concepção de uma força vital subjacente com as investigações do romantismo e idealismo alemão. Apropriadamente aqui, não se consideram forças dispersas, espalhadas nos elementos que compõem o universo, mas de uma única e mesma força que subjaz toda a matéria existente e, de formas diversas, deixa ver seu caráter ideal. Destacamos que Johann Ritter, por uma via empírica, chega também a essa concepção unitária da força que subjaz os fenômenos orgânicos e inorgânicos, entretanto, vale lembrar que J. Ritter também esteve associado com o romantismo alemão e dele absorveu a concepção orgânica que norteou sua perspectiva unitária dos fenômenos. Ele, nos seus primeiros trabalhos, efetivamente recusa $o$ caráter meramente idealista da proposta romântica, se aproximando muito mais de Goethe do que da proposta idealista de Schelling, apesar de destacarse na sua fase madura pela composição de uma ciência schellinguiana. Antes de apropriadamente entendermos se Humboldt também manteve ou não um caráter empírico como guia geral de sua atividade científica, vale pensar as possíveis relações de Humboldt com as propostas idealistas. Nesse aspecto, duas proposições filosóficas parecem bastante adequadas: a de Schelling e Schopenhauer.

\section{A FILOSOFIA E A PRODUÇÃO DE UMA CIÊNCIA HUMBOLDTIANA DO COSMOS}

Por um lado, na perspectiva de Schelling, temos que o elemento ideal é comum na produção da autoconsciência e na dinâmica da natureza, de maneira que o mesmo fundamento geral que põe 
em atividade o sujeito no conhecimento de si, numa perspectiva dialética, é o que põe em atividade o próprio mundo. É este ideal ativo que se pode reconhecer, no campo limitado da experiência sensível, como força vital fundamental, posto que é a expressão individualizada de toda a dinâmica ideal transcendental da realidade no seu duplo subjetivo-objetivo. Por outro lado, na perspectiva de Schopenhauer, há também um elemento invariável que subjaz as manifestações fenomênicas, que emerge como força atuante por detrás do jogo de representações e que, portanto, aparece como telos geral de toda a organização da natureza: a Vontade, que, como pudemos ver, também é mencionada por Humboldt. Em Schpenhauer:

Toda causa na natureza é causa ocasional, apenas dá a oportunidade, a ocasião, para o fenômeno da Vontade una, indivisa, em-si de todas as coisas, e cuja objetivação grau por grau é todo este mundo visível. Apenas a entrada em cena, o tornar-se visível neste lugar, neste tempo, é produzido pela causa, e nesse sentido depende desta, mas não o todo do fenômeno, não a sua essência íntima: esta é a Vontade, à qual não se aplica o princípio de razão, e, portanto, é sem-fundamento. (SCHOPENHAUER, 2005, p. 200)

Como tal, a Vontade é o fundamento geral de todo o existente, o fundamento primeiro que, no jogo das representações, encontra formas diferenciadas de manifestação, embora seja a mesma, tanto no desígnio humano como na força de atração gravitacional ou na excitação que impele o polo negativo na direção do positivo. Uma causa final que não é determinada essencialmente pela esfera dos fenômenos e, portanto, não é determinada pela razão e os limites esquemáticos que lhe subjazem; é a Vontade raiz teleológica da natureza e do homem, inexprimível por qualquer determinação contingente, mas livre como elemento indeterminável pela esfera limita das representações e da estrutura lógica da razão. No entanto, vale lembrar que a primeira edição do Mundo como Vontade e Representação data de 1819 , ao passo que a primeira edição dos
Quadros da Natureza de Humboldt é de 1807. Não há fundamento algum admitir que o sentido de vontade e organização natural resguarde a manifestação de uma influência ou assimilação das ideias de Schopenhauer por parte de Humboldt, tendo em vista que sua obra foi redigida e publicada mais de uma década antes do sistema schopenhauriano. Talvez o aporte em Schopenhauer como paralelo em Humboldt encontre sua fonte na valorização romântico-estética e na maneira de intuitivamente captar a unidade da cena em uma perspectiva finalística, ou seja, tenha como fundamento a mesma fonte de que se vale Humboldt na construção de seus Quadros, ou seja, tenha sua fonte em Goethe.

Como Humboldt mesmo adverte, Goethe modificou para sempre a sua forma de compreender a natureza e, como podemos conceber, muito dessa esfera intangível da existência pode estar em associação com esta relação imediata em Jena. A existência de um elemento motriz do desdobramento progressivo da realidade é parte da proposta formativa goethiana. Especialmente nas plantas, esta atividade promotora do telos universal se manifesta mais claramente e deixa ver ao olho atento as fases e estágios progressivos revelados na forma. Outra concepção, a de protótipo, é igualmente basilar, haja vista que fazendo referência à concepção classicista de Goethe, a diversidade e particularidade é a manifestação difusa, finita, do tipo universal, do invariável prototípico. Na dupla concepção de protofenômeno e protótipo a planta se apresenta como o objeto mais revelador, posto que é o mais propício ao reconhecimento do universal na forma e, ao mesmo tempo, à apresentação imediata da progressão protofenomênica nos diversos estágios formativos da forma vegetal. Basta que tenhamos claro aqui, na mera investigação da finalidade, que Humboldt, muito apropriadamente, reconhece nas plantas esse caráter superior de manifestação da força vital, do elemento oculto. Segundo ele, ainda nos Quadros da Natureza:

As plantas tendem incessantemente a dispor em combinações harmônicas a matéria bruta da terra; têm por ofício preparar e misturar, em virtude da sua força vital, as substâncias 
que, depois de inúmeras modificações, hão de ser elevadas ao estado de fibras nervosas. O mesmo olhar com que abraçamos o tapete vegetal que cobre a terra, revela-nos a plenitude da vida animal alimentada e conservada pelas plantas. (HUMBOLDT, 1952, p. 279; 1930, p. 338)

Vale notar que se esta perspectiva de um impulso na designação de um fim natural está presente na composição de Humboldt, ela certamente está associada com a sua concepção de forma, que é, de toda maneira, o modo pelo qual toda a atividade do mundo se dá a ver, especialmente no reino vegetal. A paisagem, como núcleo central de todas as suas ideias, edifica-se nessa ligação entre atividade e imediaticidade da forma.

Crucial para Humboldt, essa dupla perspectiva objetiva e subjetiva da paisagem é a chave de seu valor como elemento de análise no projeto de compreensão e interligação cósmica. Aqui, Humboldt reforça que não se trata simplesmente de captar os elementos da natureza da maneira mais fidedigna, mas de, no jogo da representação, fazer ver ao admirador da obra a conformação entre o artista e cena na realização genial da arte.

A pintura da paisagem não é tampouco puramente imitativa; tem, sem dúvida, um fundamento mais material e há nela algo mais terrestre. Exige dos sentidos uma variedade infinita de observações imediatas, que deve assimilar-se ao espírito para fecundá-las com seu poder e dá-las aos sentidos sob a forma de uma obra de arte. O grande estilo da pintura da paisagem é o fruto de uma contemplação profunda da Natureza e da transformação que se verifica no interior do pensamento. (HUMBOLDT, 1848, p. 100, trad. nossa)

Aquela alusão sistemática que fizemos a Schelling se afirma também aqui, visto que o intuito maior de Humboldt ao integrar no seu Cosmos o elemento pictórico da paisagem é justamente dar a ver os elementos que identificamos em toda a proposição romântica; ratifica, igualmente, a ideia de que a arte oferece uma síntese no tempo capaz de alargar a compreensão geral da unidade cósmica. Central aqui é, como já mencionamos anteriormente, o caráter integrador da forma, que reúne essa dupla perspectiva objetiva subjetiva no campo da representação estética e nos juízos de gosto.

A forma é fundamental em diversos sentidos, dos quais podemos destacar essencialmente três, que claramente denotam uma proposição romântica na sistematização do projeto humboldtiano do Cosmos: $1^{\circ}$. a forma representa uma comunhão entre subjetividade e objetividade; $2^{\circ}$. representa uma conformação entre todo e partes e $3^{\circ}$. reforça a ligação estético-teleológica na consideração da natureza.

A forma é mais do que simplesmente uma feição particular reconhecida, ela é, antes de mais, o ponto aglutinador de toda a atividade cósmica. Em Humboldt, é exatamente esse caráter da forma que orienta o valor atribuído à pintura da paisagem: "O homem que pode abarcar de uma só vista a Natureza, feita abstração dos fenômenos parciais, reconhece os progressos em cuja virtude se desenvolvem a sua vida e a força orgânica..." Numa recuperação dos Quadros da Natureza, em que essa perspectiva da forma aparece de maneira mais evidente, podemos ver claramente que a vista da paisagem, a contemplação da forma orgânica em seu conjunto, oferece intuitivamente uma compreensão integrada do mundo, de maneira que toda a sua atividade e transformação aparecem então envolvidas e ligadas, como de fato são, ao espírito humano que as contempla. Essa unidade é requerida como fundamento de todo o Quadros da Natureza de Humboldt e, sobretudo, constitui um papel crucial na aplicação de um método morfológico de análise.

Reforçamos aqui que toda a contemplação da cena da paisagem repousa na forma tomada em conjunto, oferecendo à intuição, assim como acontecia em Schelling, uma unidade formativa do sujeito e do objeto. É nesse sentido que duas coisas são completamente essenciais para que a pintura da paisagem apresentasse seu valor, a dizer: que se abrisse um horizonte extenso das propriedades objetivas e da diversidade que compõe a superfície da Terra e, na mesma medida, tivesse o espírito humano 
alcançado o desenvolvimento necessário para, no seio dessa natureza, tomar consciência, ainda que intuitiva, da organização progressivo-teleológica do mundo como todo orgânico.

Para que a representação das formas individuais da Natureza, no que se refere ao ramo da arte que nos ocupa, pudesse adquirir maior variedade e exatidão, era preciso que se tivesse alargado o círculo dos conhecimentos geográficos; que se facilitassem as viagens às regiões mais longínquas e que se exercitasse o sentimento na tarefa de compreender as diferentes belezas dos vegetais e dos caracteres comuns que os agrupam em famílias naturais. (HUMBOLDT, 1848, p. 95, trad. nossa)

Seja como descrição poética, seja como pintura, a paisagem revela, na forma tomada em conjunto, na cena contemplada pelo observador que a descreve ou pinta genialmente, a relação e harmonia existente entre todos os particulares e a unidade orgânica do Cosmos. A arte, assim como vimos no romantismo alemão, conforma agora o propósito geral sintético e, portanto, pelos seus diferentes meios e recursos, se dá a ver para e com o espírito humano. Como assevera Humboldt: "Multiplicando os meios em cujo auxílio se reproduz sob imagens expressivas o conjunto dos fenômenos naturais, é como melhor se familiarizará aos homens com a unidade do mundo, fazendo-os sentir mais vivamente o harmonioso concerto da Natureza." (HUMBOLDT, 1848, p. 107, trad. nossa).

Concebida no limite indeciso entre finitude e infinitude, a forma da paisagem, o recorte das formas belas sob a cadência medida das luzes e cores, confere à pintura, ou à contemplação mesmo da natureza, uma possibilidade de superar as barreiras formais do conhecimento. A arte, aglutinando aqui o caráter intuitivo da forma, condensa no imediato a propagação geral de uma multiplicidade de espécies e seres, então conformados em unidade; sob um único golpe de vista que deleita, dá ao observador uma composição harmônica que ressoa do singular ao universal. $\mathrm{O}$ tencionar entre a natureza e o indeciso limite da vegetação e do horizonte, presentes no
Gênio Ródio e circunscritos na caracterização da paisagem, marcam esse sentimento que, despertado no Sturm und Drang, faz ver de forma coerente e sistemática no idealismo romântico a progressão natural que escapa aos limites da mera consideração objetiva da ciência, daí o papel da subjetividade.

\section{CONSIDERAÇÕES FINAIS}

Pretendemosdeixarevidentenacaracterização do Gênio Ródio uma ligação importante de Humboldt com a proposta sistemática de Schelling; além de deixar clara uma conformação com as ideias de Goethe. Desde a ponderação teleológica da natureza, passando pela consideração da integração orgânica das esferas orgânica e inorgânica, até chegar ao caráter sintético da arte genial, temos que a resposta sistemática schellinguiana responde bem aos propósitos unificadores de Humboldt e parece definitivamente ter sido o caminho seguido por ele na composição do seu Cosmos e de sua Geografia. Como Schelling, Humboldt pretende uma ligação sistemática dos diferentes elementos da Terra. Aquela impressão que o guiava cegamente na infância, e que se reproduzia na capacidade integradora destacada por seu irmão, viria a tomar novas formas com a influência da Naturphilosophie romântica. "Como que dotado de novos órgãos", aquela expectativa ingênua e pouco clara se torna efetivamente uma ambição plausível, com uma marca metodológica singular que compreenderemos a seguir. Ali, nesse afã obstinado por compreender em ligação os fenômenos do mundo, pôde reconhecer a fonte maior de inspiração, a composição geral de que precisava para levar a bom termo toda sua vocação de pesquisa e integração de ideias. Concebida como totalidade num duplo objetivo-subjetivo, pode a natureza chegar a um verdadeiro conhecimento de si. Pelas mãos de Humboldt, a promessa intelectual da filosofia romântica pretendia-se cumprida; na sua capacidade laboriosa singular, conformava em unidade toda a diversidade que se apresentava diante de seus olhos. A natureza, assim compreendida, revelava um caráter progressivo, manifesto na forma, na imagem tipificada de toda a variação. Como relação todo partes, esta forma oferecia, ao mesmo tempo, 
a disposição integradora de sujeito e objeto, sem o que seria impossível a sua consideração sintética, aglutinadora. Romântica, essa disposição unitária encontra apoio na arte, na capacidade do artista genial de transpor ao espírito do homem a fluidez e progressão histórica no imediato. Em perfeita comunhão, o processo de transformação da realidade é, igualmente, o processo de desenvolvimento histórico do espírito. A produção da autoconsciência no mundo revela essa unidade e deixa ver, tanto na natureza quanto no homem, o mesmo fundamento ideal progressivo. Essa força ativa reaproxima orgânico e inorgânico numa grande expressão da vida, a imagem acabada da totalidade cósmica na limitação dos fenômenos. O propósito de Humboldt, assim, não pode deixar de mostrar, ao olho atento, que se trata de uma proposição idealista romântica afeita especialmente a Schelling e interligada metodologicamente a Goethe. O Gênio Ródio, este artigo perdido em meio às centenas publicadas de Humboldt, é o elo que liga o seu passado científico teleológico com o domínio artístico-filosófico de sua maturidade intelectual. Daí nascida, a Geografia toma forma e significação interpretativa no estudo da Terra, compreendendo no limite da visão o que está para além do recorte objetivo que se lhe oferece. A arte, a força vital e o Gênio Ródio recontam ao longo de uma vida a tarefa de ver em unidade a interligação geográfica de um Cosmos sempre vivo.

\section{REFERÊNCIAS}

BARBOZA, J. Infinitude subjetiva e estética: natureza e arte em Schelling e Schopenhauer. São Paulo: Ed. UNESP, 2005.

BENJAMIN, W. O conceito de crítica da arte no romantismo alemão. Trad. e notas Marcio Seligmann Silva. São Paulo: Iluminuras, 2002.

BESSE, J. M. Ver a Terra: seis ensaios sobre a paisagem e a geografia. São Paulo: Perspectiva, 2006.

BORHEIM, G. Filosofia do Romantismo. In: GUINSBURG, J. O romantismo. São Paulo: Editora Perspectiva, 2005, p. 75-11.
BUNKSÉ, E. V. Humboldt and an aesthetic tradition in geography. The Geographical Review, 71, n. 2, 127-46, 1981.

DIDEROT. Diálogos entre D'Alembert e Diderot. São Paulo: Abril Cultural, 1973. p. 381-390 (Os Pensadores).

ENGELHARDT. In: CUNNINGHAM, A. \& JARDINE, N. Romanticism and the sciences. New York: Cambridge University Press, 1990.

FICHTE, J. G. A doutrina da ciência de 1794 e outros escritos. Seleção, trad. e notas Rubens Rodrigues Torres Filho. São Paulo: Nova Cultural, 1988. (Os Pensadores)

FRANKLIN, J. Artifice and the Natural World: Mathematics, Logic, Technology. In: HAAKONSEEN, $\mathrm{K}$ (org.). The Cambridge history of eighteenth-century philosophy. Cambridge: Cambridge Pres, 2006. p. 815-853.

GARBER, D. Leibniz: physics and philosophy. In The Cambridge Companion to Leibniz. San Diego: Cambridge University Press, 1998.

GASCAR. P. Humboldt l'explorateu. Paris: Gallimard, 1985.

GAYET, M. Alexandre de Humboldt: le dernier savant universel. Préface Philippe Taquet. Paris: Presses Universitairies de France, 1995.

GIANOTTI, M. Apresentação. In: GOETHE, J. W. Doutrina das cores. São Paulo: Nova Alexandria, 1993.

GOETHE, J. W. von. Memórias: poesia e verdade. Porto Alegre: Editora Globo S.A., 1971.

GOETHE, J. W. von. Doutrina das cores. São Paulo: Nova Alexandria, 1993. 
GOETHE, J. W. von. A metamorfose das plantas. Trad., Introdução e Notas Maria Molder, Lisboa: Imprensa Nacional da Casa da Moeda, 1997.

GUYER, P. 18th century german aesthetics. Stanford Encyclopedia of Philosophy, 2007.

HANKINS, T. Science and the Enlightenment. Cambridge: Cambridge University Press, 1985.

HERDER, J. G. Obra selecta. Madrid: Alfaguara, 1982. pp. 131-232

HUMBOLDT, A. von. Experiencias acerca del galvanismo, y en general sobre la irritacion de las fibras musculares y nerviosas. Trad. J. Fr. N. Jadelot y D.A.D.L.M. Madrid: Imprenta de la Administracion del Real Arbitrio de Beneficiencia, 1803.

HUMBOLDT, A. von. Tableaux de la nature. Trad. Ch. Galausky. Paris: Legrand Poumey Et Crouzet Éditeurs, 1930.

HUMBOLDT, A. von. Quadros da natureza. São Paulo: W. M. Jackson Inc., Vol. 1., 1952. (Clássicos Jackson)

HUMBOLDT, A. von. Quadros da Natureza. São Paulo: W. M. Jackson Inc., Vol. 2., 1953. (Clássicos Jackson)

HUMBOLDT, A. von. Cosmos: essai d' une descripcion physique du monde. Trad. H. Faye. Paris: Gide et C. Libraires-Éditeurs, 1846. Vol. I.

HUMBOLDT, A. von. Cosmos: essai d'une descripcion physique du monde. Trad. Ch. Galusky. Paris: Gide et C. Libraires-Éditeurs, 1848. Vol. II.

HUMBOLDT, A. von. Cosmos: essai d' une descripcion physique du monde.Trad. H. Faye. Paris: Gide et C. Libraires-Éditeurs, 1851. Vol. III.

HUMBOLDT, A. von. Cosmos: essai d' une descripcion physique du monde.Trad. Ch. Galusky. Paris: Gide et C. Libraires-Éditeurs, 1859. Vol. IV.
HUMBOLDT, A. von. Cosmos: essai d' une descripcion physique du monde.Trad. Bernard Giner y Jose Fuentes. Madrid: Imprenta de Gaspar y Roig. Editores, 1874a. Vol. I.

HUMBOLDT, A. von. Cosmos: essai d' une descripcion physique du monde.Trad. Bernard Giner y Jose Fuentes. Madrid: Imprenta de Gaspar y Roig. Editores, 1874b. Vol. II.

HUMBOLDT, A. von. Cosmos: essai d' une descripcion physique du monde.Trad. Bernard Giner y Jose Fuentes. Madrid: Imprenta de Gaspar y Roig. Editores, 1874c. Vol. III.

HUMBOLDT, A. von. Cosmos: essai d' une descripcion physique du monde.Trad. Bernard Giner y Jose Fuentes. Madrid: Imprenta de Gaspar y Roig. Editores, 1875. Vol. IV..

KNIGHT, D. M. Science in the Romantic Era. Aldershot, Brookfiled USA, Singapore, Sydney: Ashgate, Variorum, 1998.

LAWRENCE. In: CUNNINGHAM, A. \& JARDINE, N. Romanticism and the sciences. New York: Cambridge University Press, 1990.

LENIOR In CUNNINGHAM \& JARDINE. Romanticism and the sciences. New York: Cambridge University Press, 1990. (pp. 119-129)

MARTINS, R. A. Alessandro Volta e a invenção da pilha: dificuldades no estabelecimento da identidade entre o galvanismo e a eletricidade. Acta Scientiarum, 1999, n. 21, vol. 4, p. 823-835. DOI: http://dx.doi. org/10.4025/actascitechnol.v21i0.3079

MATTOS, C. V. A pintura de paisagem entre arte e ciência: Goethe, Hackert, Humboldt. Revista Terceira Margem, Rio de Janeiro: UFRJ, no. 10, p.152-168, 2004. 
MILLÁN-ZAIBERT, E. Alexander von Humboldt's 'Romantic' Encounter with Latin America," Chapter Five of Alexander von Humboldt: From the Americas to the Cosmos, pp. 41-55. (http://web.gc.cuny.edu/ dept/bildn/humboldtconference/home.htm)

MOLDER In: GOETHE, J. W. A metamorfose das plantas. Tradução, Introdução e Notas Maria Molder, Lisboa: Imprensa Nacional da Casa da Moeda, 1997.

NICOLSON In: CUNNINGHAM \& JARDINE. Romanticism and the sciences. New York: Cambridge University Press, 1990. pp. 169-188.

RICHARDS, R. J. The romantic conception of life: science and philosophy in the age of Goethe. Chicago: University of Chicago Press, 2002.

RICOTTA, L. Natureza, Ciência e estética em Alexander von Humboldt. Rio de Janeiro: MAUD, 2002.

SAFRANSKI, R. Romantismo: uma questão alemã. Trad. Rita Rios. São Paulo: Estação Liberdade, 2010.

SCHELLING, F. Obras escolhidas. Sel., Trad. e notas Rubens Rodrigues Torres Filho. São Paulo: Abril Cultural, 1979. (Os Pensadores)

SCHELLING, F. Sistema del idealismo trascendental. Traducción, prólogo y notas de Jacinto Rivera de Rosales y Virginia López Domínguez. Barcelona: Anthropos, 1988.

SCHELLING, F. Ideias para uma filosofia da natureza: prefácio, introdução e aditamento à introdução. Lisboa: Imprensa Nacional Casa da Moeda, 2001a.

SCHELLING, F. Filosofia da Arte. Introd. e notas Márcio Suzuki. São Paulo: Editora da Universidade de São Paulo, 2001b. p. 09-143.
SCHOPENHAUER, A. O mundo como vontade e como representação. Tradução, apresentação, notas e índices Jair Barboza. São Paulo: Editora UNESP, 2005.

WERLE In: GOETHE. Escritos sobre arte. Introdução, tradução e notas Marco Aurélio Werle. São Paulo: Associação Editorial Humanitas \& Imprensa Oficial do estado de São Paulo, 2005.

WETZELS. In: CUNNINGHAM, A. \& JARDINE, N. Romanticism and the sciences. New York: Cambridge University Press, 1990. 